\title{
Critical success factors for e-learning and institutional change - some organisational perspectives on campus-wide e-learning
}

\section{Su White}

Su White is a senior lecturer in Electronics and Computer Science at the University of Southampton, UK. Her research in the Learning Societies Lab is concerned with organisational change and the structure, culture and climate of higher education institutions, with specific reference to technology enhanced learning. Address for correspondence Electronics and Computer Science, University of Southampton, Highfield. Southampton, SO17 1BJ. Telephone +44(0)23 8059 4471; fax: +44 (0)23 8059 3218; email saw@ecs.soton.ac.uk; Web site http://www.ecs.soton.ac.uk/people/saw/

\begin{abstract}
Computer technology has been harnessed for education in UK universities ever since the first computers for research were installed at ten selected sites in 1957. Subsequently real costs have fallen dramatically. Processing power has increased; network and communications infrastructure has proliferated; and information has become unimaginably accessible through the Internet and the World Wide Web. However, perhaps because higher education institutions are resistant to change, educational technology in universities has not managed to match the ubiquity of technology in everyday life. The reasons for differences between everyday experiences and those higher education and may lie in higher education practice. Higher education practice reflects the wider agendas of institutions manifested through their organisation, structure, culture and climate. These factors may particularly impact upon the potential for higher education to embrace and manage change in its educational activities; especially technology enhanced learning such as blended learning and e-learning. This paper briefly reviews the progress of educational technology, then identifies critical success factors for e-learning through an organisational perspective derived from studies of six UK higher education institutions.
\end{abstract}

Keywords: educational technology, e-learning, e-learning strategy, embedding higher education, higher education policy, institutional change, learning technologies, managing change, technology enhanced learning.

\section{Introduction}

This paper identifies and analyses some critical success factors for institutional change and their impact upon campus-wide e-learning from two broad perspectives. The first perspective resulted from ten years' experience of introducing learning technologies within a single UK institution. The research used evidence drawn from a series of surveys of staff attitudes to the use of computers in teaching. Interim conclusions led to the second perspective; further investigations in six different UK universities which analysed the experience of individuals fulfilling a range of key roles associated with managing and using e-learning on campus (White, 2006). The progress of educational change and educational technology across the UK is considered, before the research and evidence is presented.

\section{Background}

Systemic use of computers in education

The impetus to use computers in education followed immediately after their development in the mid $20^{\text {th }}$ Century. In the US, campus-wide initiatives developed in significant universities, 
see for example experiences reported at Carnegie Mellon University, (Kiesler and Sproull 1987). NDP-CAL began in the UK during the 1970s was a national initiative designed to take computer aided learning out of the laboratory (Hooper, 1975). Its successor, the Teaching and Learning Technology Programme (TLTP) specifically addressed earlier conclusions, developing subject resources and institutional approaches for "effectiveness and efficiency" (Turpin, 1994; HEFCE, 1996). E-learning's progress has been documented from disciplinary and institutional perspectives (Hammond et al, 1992; Kind and Radtke, 1995; White and Maier 1998). Much analysis continues to be published from the learners' or teachers' perspective, but some recent work has considered institutional strategies for change (McNaught and Kennedy, 2000; Surry, 2000; Twigg, 2001; Nicolle, 2005; Salmon, 2005).

\section{Systematic management}

During the 1990s policy makers were promoting more systematic approaches to university management procedures related to e-learning (White, 2000). Follet called for information system strategies and greater use of strategic planning processes while MacFarlane presented a vision for the future (Follett, 1993; MacFarlane, 1992; MacFarlane, 1995). There followed technically and educationally motivated initiatives to create and embed e-learning. The UKwide Joint Information Systems Committee established pilot projects to identify and disseminate good practice in developing an Information Strategy accompanied by briefings for senior managers (JISC, 1995). This work is continued through their Organisational Support Committee. HEFCE introduced a teaching quality enhancement fund to promote institutional ownership of educational good practice including "innovations in learning and teaching, especially in the use of communications and information technology" (HEFCE, 2001). This programme also continues.

\section{First Perspective: A Single Institution}

Scholar was a three year project begun in 1993 at the University of Southampton. It had a remit to "Shift the culture of the University", coupled with an objective of establishing a “Campus Wide Structure for Multimedia Learning”. It used a hypermedia system in mini projects to author sets of educational resources (White, 1993; Hall et al, 1995). This activity was complemented by extensive staff and educational development activities focussing on using and embedding e-learning.

In order to gauge the extent of change effected by Scholar, three attitudinal surveys were conducted in 1993, 1996 and 2000. The original survey format was based other TLTP work (Doughty, 1994) which was widely disseminated and adapted (Bailey, 1996). Interim analysis has already been published (Barnett et al, 1998).

The survey provided evidence of a steady growth in the use of e-learning during the lifetime of the project and a subsequent broadening of its distribution. Initially there was greater use amongst science, technology and medical disciplines, in the later surveys use in the arts and humanities had increased. However alongside the background increase in technology use, the World Wide Web had been introduced while the unit cost of hardware and communications infrastructure had fallen; the observed effects may not have resulted from the interventions of the Scholar Project. Funding sets of mini projects had been the main mechanism of initiating educational change used by Scholar, and it was apparent that a few years after funding had ceased only a rump of activity remained. Furthermore, it was difficult to see how to generate the impetus to sustain new e-learning activities, given the conflicting demands on academics' time in the research intensive environment which prevailed at Southampton. 
There is extensive general literature on change; Rogers is much cited (Rogers, 1983) and Lewin's force-filed analysis considering equilibrium in systems is applicable in an educational context (Lewin, 1952). Elton based a pedagogically oriented change management framework around this view (Elton, 1999). It has also been noted that behaviour in academic institutions in inevitably linked to disciplinary contexts (Trowler, 1998, Becher and Trowler 2001); e-learning applications should also take that context into account (White and Liccardi, 2006). However for this research Geoghegan's socio-technical viewpoint, specifically related to instructional technology, offered a theoretic perspective which seemed particularly relevant to the university-wide e-learning experience (Geoghegan, 1994, 1998). His work considered needs of the educational mainstream, developing ideas from Moore's analogy of "crossing the chasm" between the early adopters and the early majority (Moore, 1991). He explained the difference between barriers and success factors for change, but set them in the context of the use of computers in academia. The academics who worked on the Southampton mini projects had been early adopters. The mainstream encompassed those whose participation was needed if the project was to succeed and shift the culture. Geoghegan's differentiation between the needs of the early adopters and the needs of the mainstream is shown in Table 1 below.

\section{Table 1: The differing needs of early adopters versus the mainstream, adapted from} Geoghegan

\begin{tabular}{ll}
\hline Early Adopters & Mainstream \\
\hline Like radical change & Like gradual change \\
\hline Visionary & Pragmatic \\
\hline Project oriented & Process oriented \\
\hline Risk takers & Risk averse \\
\hline Willing to experiment & Need proven uses \\
\hline Self sufficient & Need support \\
\hline Relate horizontally & Relate vertically \\
\hline
\end{tabular}

Reflecting on Geoghegan's observations and the experience of the Scholar Project, it was apparent that although the Scholar Project initially set out to work in the mainstream, it had been structurally constrained. The project framework bound activities to early adopters, and methods which appeared to reach the mainstream lost impetus after project funding ceased. Among the questions which followed on from these observations were:

Are there aspects of the academic process in the UK, specific to the culture of individual institutions, which identify the best routes to the change and innovation?

Does the organisational structure of a university in itself effectively select an academics propensity to adopt and integrate new technologies into their teaching?

In order to explore possible responses to these questions further, a series of interviews were conducted across six institutions (White 2006). The next section describes this process and highlights some of the key findings from these interviews. 


\section{Looking into experience}

Semi-structured interviews were conducted with thirty-eight subjects in six universities which were broadly similar in terms of size and total teaching numbers to the University of Southampton. They represented a range of institutional types; from those for whom the majority of income was derived from teaching ('teaching-intensive') through to those where the majority of income was derived from research and consultancy ('research-intensive'). The differentiation between research intensive and teaching intensive was chosen not because there is a large difference between educational activities within the two types, but because of differences in overall activities and financial realities as shown in Figure 1 and discussed further below.

\section{Figure 1: Comparison of typical managerial perceptions of context and values expressed in different institutions}

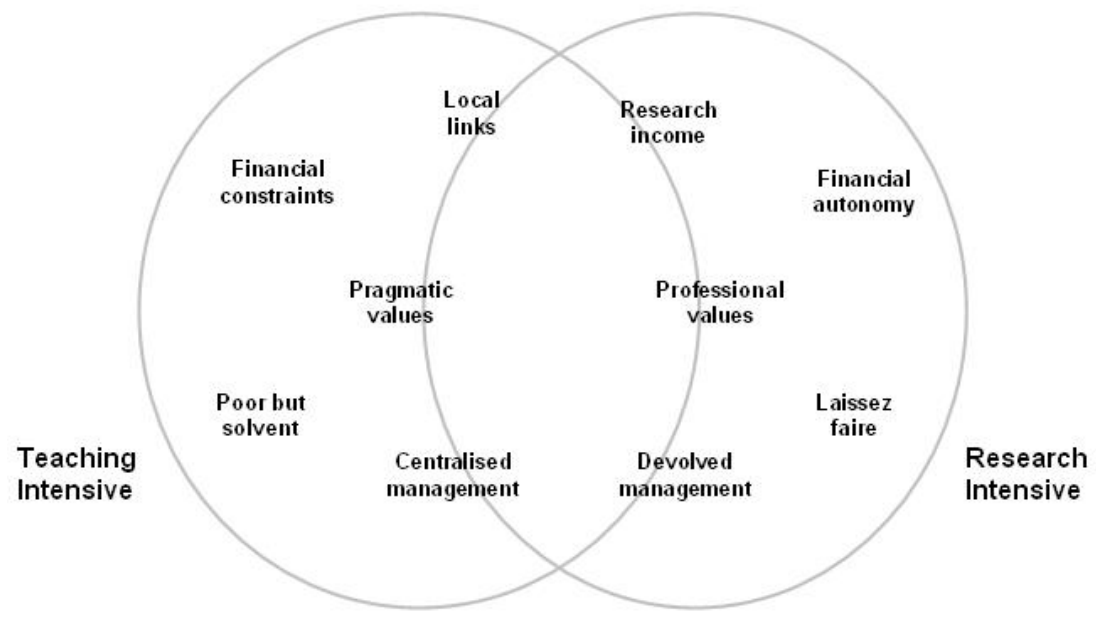

Subjects were selected using a chain sampling technique seeded by acknowledged sources of expertise to represent a range of experiences across the institution. All initial interviewees held senior positions in their respective institutions. The total set of subjects fell into three broad groups, university level managers; academic champions and local experts; and staff working in the professional services. Ten of the interviews were with individuals who held higher managerial responsibility in their institution. Nine interviewees (both higher managerial and individuals with senior levels of responsibility) were part of the professional services. Eleven of the interviewees had high levels of technical expertise directly related to learning technologies. They had all been actively involved in activities which introduced, used and evaluated learning technologies in student education. Nine of those interviewed came from an academic perspective, and five of the interviewees who were in managerial responsibilities or the services had previously been active academics. Parallel analysis was undertaken of existing data in the public domain, for example, institutional strategy documents and numerical information published by the UK Higher Education Statistical Agency (HESA).

The aim was to explore how individuals and institutions experienced the drivers and barriers to change in the specific context of the introduction, use and uptake of learning technologies in their individual institutions. It as intended that the data previously collected at the microlevel would contribute to an analysis at a meta-level. Respondents in the original survey had overwhelmingly pointed to "lack of time" as being a limiting factor - yet a good number of 
respondents (the early adopters) had apparently overcome this limitation; perhaps the bigger question is how can institutions enable change (and perhaps alter academic's perceptions of lack of time). Information would be needed from institutional managers to explore these issues. The initial survey had only questioned academic and teaching support staff and could not address the way in which the use of e-learning might be moderated or motivated beyond of the immediate teaching context. Understanding the needs of the mainstream demanded a broader survey, and Geoghegan's emphasis on vertical connection needed information from all levels of the vertical chain. Another observation was that early adopters in the Southampton experience had come from traditionally wealthy areas. Was finance more important than educational motivation?

The interviewees identified differences between experience in the research-intensive and teaching-intensive institution. Key contexts and managerial approaches which emerged during the interview process are summarised in Figure 1. The information is presented as a Venn diagram to indicate that there are of course overlaps in approaches. The information presented illustrates the key differences.

Institutions which had achieved the greatest extent of the use of e-learning reflected a more consistent understanding of the objectives and benefits of using technology in their particular institutional context. This was true irrespective of whether the institution was researchintensive or teaching-intensive. Institutions might choose to make strategic use of funds to develop e-learning and the associated infrastructure. In institutions where it was perceived that finance was limited managers expressed their motivations for change in clear instrumental and strategic terms.

Mechanisms: strategy, policy, processes and tactics

A variety of mechanisms were observed which can bring about change. At the top level, strategy sets objectives and articulates institutional ambition. Policy provides guidance and a framework within which strategy can be realised. Processes may be routines which support strategy but are not articulated in the same clear manner as policies. At a more practical and pragmatic level, individuals devise and utilise tactics which can bring about or support change.

All institutions studied had learning and teaching strategies - some had solely a learning teaching and assessment strategy, some incorporated an e-learning strategy, others had a separate but associated e-learning strategy. Often the documents were available in the public domain, but where this was not the case, managers were happy to make a copy available for the purposes of this research. All institutions had seen a number of iterations of their strategies and had used a system of working groups and committees, and consultative ratification of the teaching and learning strategy.

The role of HEFCE and the JISC in motivating the development of these strategies was widely acknowledged. All institutional managers pointed to ways in which the institution had used funds to benefit the use of learning technologies in their institution, and interviewees acknowledged the value of external drivers in enabling them to take forward the agendas identified in the strategy. Although institutions have been using HEFCE funding from to direct strategy, some academics were more equivocal about the impact of the strategies. "I don't know whether it impacts on academics at an individual level. I wonder .... I have wondered in the past whether we have really had a strong focal point for strategic development for, let's say, e-learning broadly”. Similarly although there was widespread 
reference by the managers to external strategy documents such as the HEFCE e-learning strategy (HEFCE, 2005), these were not typically referenced by the non-managers.

Some institutions had also created explicit policies on learning and teaching, or e-learning, and in those instances managers emphasised the importance to their institution of the existence of such policies. Policies typically existed in institutions with a more managerial approach. Those institutions with a mixed approach to management often pointed to policies which were incorporated into documents such as the variously named Quality Manuals and the Tutors Handbooks. In these instances it was implicitly acknowledged that the existence of learning and teaching policies and the e-learning policies had also been influenced by the external driver of the Quality Assurance Agency (QAA).

Professional services can be seen as a structural device which can achieve goals consistent with the ambitions of the institution. Their potential to drive and direct change was not lost on the professional managers who were interviewed, for example: "People work from a professional perspective to drive innovation because professionally this is part of the role and you are then changing the culture without having to go for structural change". It was acknowledged that managerial and strategic approaches vary across the sector. "The trouble with you researchers is you make us think about what we are doing and why we are doing it". If some approaches may be more successful than others depending upon the situation and circumstances of the institution, then the value of self understanding becomes all the more important.

Managers interviewed showed an interest in the work of other institutions and the progress which was being made. One interviewee pointed to a conversation they had had with a Pro Vice Chancellor at another institution. Both had made use of TQEF funds to address some aspects on the e-learning agenda. The other institution had taken a strongly managerial approach, defined a timetable of objectives, targets and measured outputs. The interviewee's institution had taken a less formal approach, but had provided infrastructure and rewarded and recognised good practice. "But when we compared progress we were just about at the same place forward". In both cases the change had been institutionally contextualised. Some managers saw policies and processes put into place as a means for furthering agendas. "The TQEF was a great bonus for us over a number of years, we have used it for a number of agendas over a number of years... we have had supplementary money which we could use for a number of agendas...particularly around transition, assessment was a key issue...all these things were sort of drivers. I think e-learning benefited from that".

Other managers explained how short term funding from central initiatives provided pump priming for support activities and "if it works the faculties will find a way to pay for them". Managers also referred to the general approach which they took, or which was adopted in their institution, describing it in pragmatic terms... "I don't think.., we have been strongly managerially driven in what we have done..... We got to a point where we realise yes we've got to do that if we are now to be able to move it along and there is going to be more general take up, so its been benevolent management... wherein that systemic change can take place....There would be those who feel we have not been managerial enough, I know some of my colleagues think we should have laid the rules down much more strongly and we should have had requirements and we should you know have targets and outputs and what have you". Taken together, the responses largely confirm that external initiatives have the potential to modify the actions of an institution. However, there may be limitations in the strength of this influence. "There is a worry in the sector that we don't get joined up thinking, we seem to 
see different agendas for example from the QAA, The Academy HEFCE, JISC”. None the less, external pressures do have some impact albeit mediated by local circumstances.

Tactics adopted by individual academics varied according to their motivations. They ranged from experiments designed to change teaching methods which could also lead to publishable research, to the introduction of approaches designed to tackle a real problem, such as overload on assessment as a consequence of greater student numbers. Amongst the nonmanagers, academics across both institution types identified pragmatic approaches as powerful drivers for change. A number identified the potential for computers to address time and workload issues which are associated with providing adequate feedback and assessment of student learning. "The biggest time constraint on an academic who's involved in teaching [is] assessment, ... a real high priority that the technology can be used to underpin assessment, so that we can use computer-aided assessment”.

In some institutions (both from teaching-intensive and research-intensive), quality assurance processes were in effect used as device or tactic for achieving the objectives of the learning and teaching or e-learning strategy. When questioned, managers were sensitive to the tensions between the needs of quality assurance processes and the objectives of quality enhancement initiatives. Managers and non-managers spoke of initiatives designed to "improve the student experience" or seen as "how we make learning better". There was evidence of institutional tactics which were sensitive to predominant cultures: "Our learning and teaching strategy has a goal which is to support and to develop innovative forms of learning and teaching. So to try and do this in this research led institution, we actually took some of the HEFCE money and we took some of the University money and we created a pot of funds”.

Institutions also developed tactics which addressed beliefs predominant in their institutional culture. At one institution an academic remarked ruefully that as far as getting more widespread use of learning technologies was concerned "staff development does not work". A manager at another institution explained that they did not run formal staff development courses on e-learning. Their approach was to ensure that the procedures associated with establishing an e-learning teaching resource were conditional on processes which ensured that the relevant staff were involved in appropriate development activities (effectively "justin-time" and "just-for-you"). The development activity embedded into the process of setting up the e-learning activity. It was directed to a particular need, at a particular time, and did not take place as general e-learning staff development.

Computer systems such as managed or virtual learning environments were seen also as a means of solving problems such as reaching off campus students and accommodating mixed attendance patterns. However, there were also reservations about the institutional preferred learning environment. Managers who took a pragmatic approach looked to capitalising on local activities that were started by teaching colleagues. "We have put a tremendous amount of energy into the development of CAA" was just one example where small local services such as assessment and learning environments were then pursued at an institutional level.

\section{Conclusions}

The experience of an institutional project which tried with limited success to embed elearning after the end of project funding is not unusual. The local factors which undermine the continuation of project activities are often explained in terms which are specific to the home institution. However, when the experience of many projects and initiatives at different institutions are considered, it seems that there are some common threads. 
In the UK there are some differences between the research intensive universities and the teaching intensive universities. The source of these differences might be caricatured as large differences in total wealth (research: rich, teaching: poor), management style (research: collegial, teaching: managerial), varying levels of motivation to innovate teaching (research: less motivated, teaching: focused because of cash), variations in the explicit drive to change teaching (research: teaching policies distributed or implicit, teaching: teaching policies centralised, explicit).

However, the big picture can be misleading; and managers willingly acknowledge the similarities between the objectives of their roles, understanding that their actions and approaches will be moderated by institutional contexts. Irrespective of institutional type, some departments are more wealthy and powerful than others. Research income can enable financial autonomy within an institution, but so can high income levels associated with niche teaching activities. Where there is autonomy, direct management is more difficult.

Institutions that are "poor but solvent" are more likely to have tight financial management, and more likely to engender the vertically integrated approaches which Geoghegan identified with success in crossing the chasm to the mainstream. Areas of autonomy funded through teaching may result in good local solutions related to e-learning, but will not necessarily extend across the entire institution. Institutions with widespread autonomy may have pockets of excellence but are unlikely to automatically demonstrate broad advances in e-learning.

The challenge for key decision makers lies in identifying the reality of the local circumstances and working with the existing strengths. The role of external drivers from organisations such as HEFCE, JISC and the QAA is acknowledged, and should be used for pump priming; the challenge remains 'how do we sustain change?'. This research has identified the importance of contextual analysis. There are overlaps in the experiences of institutions of different types within this survey. Future work which analyses a wider range of institutional experiences from an institution wide strategic perspective would be of great interest. Such work might enable a clearer understanding of ways in which to work within the framework on institutional context.

A pragmatic decision-maker might use sources of strategic funding to set up an institutionwide approach of small, but systematic advances building upon existing pockets of excellence. Such an approach would answer the needs of the risk-averse mainstream for processes rather than projects, proven uses and strong vertical alignment of activities. Decision-makers can easily identify early adopters, their challenge is to develop and harness the early adopter's energy as a lever for systemic change. The tools of decision makers make use of structure, strategy, policies, procedures and tactics. Much of the existing debate on the effectiveness of e-learning has focussed on classroom tactics rather than institutional, sociotechnical tactics. If we are to believe Geoghegan, we should apply our judgement to select the mix of approaches which will answer the needs of the mainstream. Moving initiatives into the mainstream may require introducing systematic challenges and changes to existing practice. The ubiquitous technology of everyday life may be simple (for example text messages) but its impact can be transformational.

The financial stringency which pertains in the teaching-intensive institutions may be a strength in terms of providing a climate which, in the hands of insightful decision makers, can be harnessed to drive widespread institutional change. The more financially autonomous climate typified by a research-intensive institution may need a structure of internal rewards coupled with explicit initiatives to build vertical alignments. Between the two extremes are a whole range of possibilities. Institutions may find it beneficial to establish long-term critical 
friends or strategic alliances with like institutions and work with these allies to identify their individual barriers to change, and thus begin to identify what in the context of their own institution will be their own critical success factors.

\section{References}

Bailey, P. (1996) Technology Supported Learning: Attitudes to Technology in Teaching, Learning and Assessment Plymouth, UK, University of Plymouth.

Barnett, L., Maier, P. \& Hothi, J. (1998) Reviewing IT Use for Teaching and Other Purposes at the University of Southampton. Internal Report. University of Southampton.

Becher, T. \& Trowler, P. (2001) Academic Tribes and Territories : Intellectual Enquiry and the Cultures of Disciplines, Buckingham, Open University Press in association with The Society for Research into Higher Education.

Doughty, G. (1994) Using Learning Technologies: Interim Conclusions from the Tilt Project. Glasgow, University of Glasgow.

Elton, L. (1999) New Ways of Learning in Higher Education: Managing the Change. Tertiary Education and Management, 5:3, 207-225.

Follett, B. (1993) Libraries Review Group: Report (the Follett Report). Bristol, Joint Funding Council.

Geoghegan, W. H. (1994) Whatever Happened to Instructional Technology? in Bapna, S., Emdad, A. \& Zaveri, J. (Eds.) 22nd Annual Conference of the International Business Schools Computing Association (IBSCA). Baltimore, Maryland, IBM.

Geoghegan, W. H. (1998) Instructional Technology and the Mainstream: The Risks of Success. in Oblinger, D. G. \& Rush, S. C. (Eds.) The Future Compatible Campus: Planning Designing and Implementing Information Technology in the Academy. Bolton, Mass, Anker.

Hall, W., Hutchings, G. \& White, S. (1995) Breaking Down the Barriers: An Architecture for Developing and Delivering Resource Based Learning Materials. World Conference on Computers in Education. Birmingham, UK.

Hammond N., G. N., Heath S., Kibby M., Mayes T., McAleese R., Mullings, C., Trapp A., (1992) Blocks to the Effective Use of Information Technology in Higher Education. Computers and Education, 18:1-3, 155162.

HEFCE (1996) Evaluation of the Teaching and Learning Technology Programme. Bristol, UK, Higher Education Funding Council for England (HEFCE).

HEFCE (2001) 01/37 Strategies for Learning and Teaching in Higher Education: A Guide to Good Practice. Bristol, Higher Education Funding Council for England (HEFCE).

HEFCE (2005) HEFCE Strategy for E-Learning 2005/12. Bristol, UK, Higher Education Funding Council for England (HEFCE), http://www.hefce.ac.uk/pubs/hefce/2005/05_12/ Last accessed 21 February 2006.

JISC (1995) Guidelines for Developing an Information Strategy. Bristol, Joint Information Systems Committee.

Kiesler, S. \& Sproull, L. (1987) Computing and Change on Campus, Cambridge, Cambridge University Press.

King, T. \& Radtke, A. (1995) Critical Factors in the Adoption of Computer Aided Learning in Higher Education. CAL'95 Cambridge.

Lewin, K. (1952) Field Theory in Social Science : Selected Theoretical Papers, London, Tavistock Publications in collaboration with Routledge \& K.Paul.

MacFarlane, A. G. J. (1992) Teaching and Learning in an Expanding Higher Education System. Edinburgh, Committee of Scottish University Principals.

MacFarlane, A. G. J. (1995) Future Patterns of Teaching and Learning. in Schuller, T. (Ed.) The Changing University? Buckingham, Open University/SRHE.

McNaught, C. \& Kennedy, P. (2000) Staff Development at Rmit: Bottom-up Work Serviced by Top-Down Investment and Policy. ALT-J, 8:1, 4-18.

Moore, G (1991) Crossing the Chasm: Marketing and Selling Technology Products to Mainstream Customers

Nicolle, P. S. (2005) Technology Adoption into Teaching and Learning by Mainstream University Faculty: A Mixed Methodology Study Revealing the 'How, When, Why, and Why Not'. Educational Leadership, Research \& Counseling. Louisiana State University.

Rogers, E. M. (1983) Diffusion of Innovation, London, Macmillan.

Salmon, G. (2005) Flying Not Flapping: A Strategic Framework for E-Learning and Pedagogical Innovation in Higher Education Institutions. ALT-J, 13:3, 201-218.

Surry, D. W. (2000) Strategies for Motivating Higher Education Faculty to Use Technology. Innovations in Education and Teaching International, 37:2, 145-153.

Trowler, P. (1998) Academics Responding to Change New Higher Education Frameworks and Academic Cultures, Buckingham, Society for Research into Higher Education Open University Press.

Turpin, S. (1994) TLTP Institutional Case Studies. Bristol, UK, TLTP. 
Twigg, C. A. (2001) Innovations in Online Learning: Moving Beyond No Significant Difference, Center for Academic Transformation, Rensselaer Polytechnic Institute.

White, S. (1993) Scholar - a Campus Wide Structure for Multimedia Learning. AETT Annual Conference: Designing for Learning. University of Strathclyde, Glasgow, Kogan Page.

White, S. (2000) Quality Assurance and Learning Technologies: Intersecting Agendas in UK Higher Education. Quality Assurance in Education, 8:1, 7-15.

White, S. A. \& Liccardi, I. (2006) Harnessing Insight into Disciplinary Differences to Refine E-Learning Design. 36th Annual ASEE/IEEE Frontiers in Education San Diego CA, IEEE.

White, S. \& Maier, P. (1998) Building Models Which Enable Change: An Examination of the Teaching and Learning Technology Support Network. Bringing Information Technology to Education (BITE). Maastricht, University of Maastricht.

White, S. A. (2006) Higher Education and Learning Technologies: An Organisational Perspective. Electronics and Computer Science. Southampton, UK, University of Southampton. 